\title{
Interdisciplinaridade e educação ambiental: uma análise bibliométrica de periódicos publicados entre 2017 a 2019
}

\author{
Interdisciplinarity and environmental education: a bibliometric analysis of \\ journals published between 2017 and 2019
}

\author{
Leonardo Dorneles Pereira ', Jefferson Marçal da Rocha II
}

\begin{abstract}
RESUMO
O presente trabalho teve como objetivo fazer uma análise bibliométrica nos periódicos da CAPES sobre os temas: interdisciplinaridade e educação ambiental. Foram analisados 85 artigos, dentre os anos de 2017 a 2019. Buscou-se nesta investigação dados referentes a gênero, metodologia, sexo dos autores, palavras-chave, área de conhecimento, regiões e países, temas mais abordados, existência de resultados e instituições mais citadas. A partir da análise dos dados foi possível correlacionar os termos interdisciplinaridade e educação ambiental com vários temas de diversas áreas do conhecimento, dentro de um contexto de análises da complexidade que os temas requerem, reforçou-se a ideia de que estes temas estão exigindo novas teorias e metodologias, que integrem o rigor científico do pesquisador com a criatividade analítica do educador. Desafio posto aos pesquisadores/educadores dos temas supracitados.
\end{abstract}

Palavras-chave: Interdisciplinaridade; Educação ambiental; Bibliometria.

\section{ABSTRACT}

The objective of this work was to carry out a bibliometric analysis in the CAPES journals on the themes: interdisciplinarity and environmental education. We have analyzed 85 articles from the years 2017 to 2019. This investigation sought data regarding gender, methodology, authors' gender, keywords, area of knowledge, regions and countries, most discussed themes, existence of results and institutions most cited. From the data analysis, it was possible to correlate the terms interdisciplinarity and environmental education with several subjects from different areas of knowledge, within a context of analysis of the complexity that the themes require. It was reinforced the idea that these themes are requiring new theories and methodologies, which integrate the scientific rigor of the researcher with the analytical creativity of the educator. Challenge posed to researchers/educators of the aforementioned themes.

Keywords: Interdisciplinarity; Environmental education; Bibliometry.

\footnotetext{
I Bacharel em Gestão Ambiental, Universidade Federal do Pampa. E-mail: leonardodornelespereira@gmail.com. ORCID: https://orcid.org/0000-0002-9087-3125.

" Jefferson Marçal da Rocha, Universidade Federal do Pampa. E-mail: jeffersonmrocha@gmail.com. ORCID: http://orcid.org/0000-0002-5873-0992.
} 


\section{INTRODUÇÃO}

O termo interdisciplinaridade não possui um sentido único, mais que um conceito, se trata de uma nova concepção de ver os preceitos conceituais disciplinares. Muitos educadores, principalmente os ligados as ciências ambientais, têm discutido a décadas, perspectivas para uma conceituação mais exata. Mesmo não sendo possível resumir todos os conceitos em um só, aqui arrisca-se uma síntese: seria um método de organização e produção do conhecimento, que interliga todos os fenômenos sociais e ambientais (FLORIANI, 2000; ROCHA, 2011).

Já quanto as práticas educativas, a interdisciplinaridade propõe mudanças na maneira de ensinar e de aprender, pois supera a visão fragmentada e parte do pressuposto de evolução, no que tange currículos, metodologias, atividades práticas e construção de uma nova ideia em relação ao conhecimento. No ensino interdisciplinar, não se pode pensar somente em reunir disciplinas ou métodos, mas sim implica novidade, ou seja, é uma abertura mediada pelo conhecimento diversificado (NOAL et al, 1998; SATO; CARVALHO, 2005; FAZENDA, 2005).

De acordo com Fazenda (2005), o ganho com as estratégias interdisciplinares nas práticas educativas melhora a interação metodológica e na transmissão/recepção do conhecimento. Para os alunos as práticas que interagem diversas áreas do conhecimento proporcionam maior coletividade, a compreensão do mundo em que estão inseridos. $O$ conhecimento passa a ser materializado em toda a sua complexidade.

Nesse contexto de mudança e formação de um novo pensamento para o ensino é possível correlacionar o conceito da interdisciplinaridade com os fundamentos da Educação Ambiental, visto que nessa perspectiva o conceito de educação é amplo e visa uma nova consciência; em relação não só aos aspectos naturais, mas também se volta para o desenvolvimento social e humano. Conforme Bradalise et al. (2017), a interdisciplinaridade desenvolve o pensamento crítico sobre as questões ambientais, nas suas interações com a sociedade. A educação deve ser holística e ter a preocupação com a preservação dos recursos naturais, sendo capaz de envolver a tríade: homem, natureza 
e universo. É importante salientar que a EA faz parte da educação, as questões ambientais devem ser encaradas como questões sociais e é através de uma visão interdisciplinar, que se passa a perceber-se à natureza como parte da sociedade (LEFF,2001).

Com intuito de investigar a inter-relação entre a educação ambiental e o conhecimento interdisciplinar esta pesquisa trata-se de uma análise bibliométrica, quantitativa e estatística, que avalia publicações nos periódicos científicos da plataforma CAPES entre 2017 e 1019 (FERREIRA, 2011).

\section{EDUCAÇÃO AMBIENTAL COM CARÁTER INTERDISCIPLINAR}

A problemática ambiental, assim como a educação ambiental ressurge como ferramenta essencial na formação pedagógica e social. É importante ressaltar que a temática da educação ambiental está embasada em um projeto teórico/prático que visa estabelecer uma sociedade mais justa e igualitária para todos, usando de medidas que estimulem um pensamento de formação do homem como agente ambiental. Diante do exposto, é possível identificar que a educação ambiental e a interdisciplinaridade funcionam como um motor gerador de criatividade e ao mesmo tempo critica uma realidade existente no processo educacional (NASCIMENTO; MENDES; BEZERRA, 2018; TRISTÃO, 2012)

Para Guimarães (2000), a educação ambiental facilita o desenvolvimento de todos os indivíduos presentes na sociedade, não apenas as crianças. Quando se trata de educação ambiental, não devemos pensar apenas nos limites escolares, mas sim em toda sociedade, educadores bem como grades curriculares.

Educação Ambiental é uma forma de educar e aprender, tendo como objetivo o próprio meio ambiente em que vivemos e a melhoria da qualidade de vida. A educação Ambiental inclui estudos de problemas ecológicos e regras de conservação da natureza, ao mesmo tempo que desenvolve tópicos de outras matérias, buscando e aplicando toda aprendizagem no próprio ambiente que envolve a classe [...] (NISKIER E MENDES,1991, p.6 Apud GUIMARÃES,2000, p.42). 
Como se pode verificar nessa citação, EA é entendida como práticas e atividades interdisciplinares. A sua aplicação propõe construir uma sociedade com novos valores sociais e culturais, formando pensadores críticos capazes de desenvolver novas práticas ambientalmente corretas (TAGLIAPIETRA E CARNIATTO, 2019). Neste contexto o professor tem um papel fundamental no processo de ensino/aprendizagem, desenvolvendo ações teórica e práticas que possibilitam aos estudantes à desenvolverem uma competência socioambiental capaz de estimular sua família e ou comunidade.

No brasil, conforme a Lei 9.795 (BRASIL, 1999, art. $1^{\circ}$ )

Entendem-se por educação ambiental os processos por meio dos quais o indivíduo e a coletividade constroem valores sociais, conhecimentos, habilidades, atitudes e competências voltadas para a conservação do meio ambiente, bem de uso comum do povo, essencial à sadia qualidade de vida e sua sustentabilidade. Ainda à Lei 9.795 (BRASIL, 1999) "Entende-se por educação ambiental na educação escolar a desenvolvida no âmbito dos currículos das instituições de ensino públicas e privadas [...]". Porém a educação ambiental ultrapassa os limites escolares, quando difundida na sociedade, sendo assim denominada educação ambiental não-formal.

Educação Ambiental não-formal, que ainda segundo o artigo 13 da Lei 9.795 (BRASIL, 1999), entendem-se pelas ações e práticas educativas voltadas à sensibilização da coletividade sobre as questões ambientais e à sua organização e participação na defesa da qualidade do meio ambiente.

Para Ayres e Filho (2007, p.3):

Habitualmente, se insiste na tese segundo a qual a Educação Ambiental constitui uma transversalidade, no sentido estrito em que esta não se esgota em uma mera abordagem disciplinar e desta maneira, além de requerer uma confluência de disciplinas e saberes, sejam esses científicos e não científicos, também requer atitudes éticas com relação a nossa inserção no mundo em que vivemos.

Logo, é importante compreender que não é apenas para o cumprimento dos aspectos legais, mas também está relacionado aos problemas ambientais que nos cercam, provocando assim a necessidade de formar profissionais aptos a trabalhar com essa nova perspectiva no processo educativo. (GUIMARÃES, 2000). De um modo geral, com uma perspectiva mais totalizada a educação ambiental e a interdisciplinaridade buscam através de apostas metodológicas inovadoras, informar e estimular a 
participação dos educadores ambientais, sensibilizando-os a participar de ações que assegurem a melhor qualidade de vida e melhor interação do ser humano dentro deste contexto. Diante do citado, é visto que se torna essencial a disseminação da necessidade da interdisciplinaridade, porém como qualquer ação que precise de sensibilização, muitas vezes não evolui no meio social.

\section{INTERDISCIPLINARIDADE EM TODAS AS ÁREAS DO CONHECIMENTO}

Inicialmente a interação homem e natureza era caracterizada como harmônica, reafirmando o equilíbrio entre os ecossistemas. Com o passar do tempo, o crescimento populacional e tecnológico tornara-se os principais responsáveis por intensificar a ação do homem sobre a natureza, quebrando o equilíbrio antes estabelecido. Nesse contexto, pode-se sintetizar que a relação homem e natureza tem apresentado alterações significativas (SANTOS, 1992).

Com intuito de promover uma relação mais ampla e integradora entre homem e natureza, os conceitos de educação ambiental e interdisciplinaridade se interligam de forma significativa. De acordo com Boff (2016), a educação com enfoque na ecologia precisa sair do conceito teórico e voltar-se para a realidade, para as experiências. Tratase de vivenciar a realidade de forma ativa e interdisciplinar, resgatando a totalidade e integrando as várias áreas do conhecimento.

A educação ambiental deve promover novos cenários, assim como a formação de indivíduos mais críticos e capazes de desenvolver uma convivência harmônica entre homem e natureza (MEDINA e SANTOS, 1999). A Educação Ambiental está diretamente relacionada com a educação, pois incorpora a ações ambientais e da sociedade, com objetivo de promover um bem-estar social e estimular o pensamento crítico e inovador (LEÃO e SILVA, 1999). Para tanto é importante ressaltar que o termo interdisciplinaridade surge como explicação à organização desse pensamento, ao invés de fragmentação há unificação do conhecimento dentro de sua complexidade social e ambiental (CARVALHO 1998). A interdisciplinaridade, a partir do início da década de 1970, surgiu como uma 
possibilidade de romper com as práticas obsoletas, proporcionando níveis de integração do conhecimento. O conceito em si estimula o pensamento crítico, pois ao invés de delimitar a ação humana exige uma postura mais dinâmica e ativa. Dentro do contexto social, as mudanças geradas pela interdisciplinaridade são responsáveis pela intercomunicação dos saberes e pela ampliação do conhecimento, pois unifica as ciências.

De acordo com Fábrega (2004), as mudanças geradas por esse processo exigem tempo de adaptação para que sejam efetivamente aceitas, maturadas e legitimadas. Conforme Fazenda (2003), uma das bases da interdisciplinaridade é a humildade, característica que demarca a intrepidez das perguntas que o homem faz ao mundo. Já para Coimbra (2000), dizer que o termo em questão está relacionado com várias áreas do conhecimento só reafirma a ideia de unificação entre duas ou mais disciplinas, estabelecendo vínculos entre si, cada profissional que se dispõe a participar desse processo de inovação expõe o conhecimento da sua área específica. As ciências biológicas e humanas, antes tratadas separadamente, com o advento da interdisciplinaridade se aproximam e possibilitam a transformação do comportamento humano, revalorizando o estudo humanístico e ampliando a compreensão da sociedade e do mundo (ROCHA, 2003; SANTOS, 1988).

Logo, unir a educação ambiental e interdisciplinaridade possibilita identificar o pensamento integrador, de perspectiva interdisciplinar em todas as áreas do saber.

\section{METODOLOGIA}

A presente pesquisa é do tipo quantitativo, onde a técnica utilizada foi a bibliométrica. Para tanto, a pesquisa realizou um recorte com as seguintes palavras: "Interdisciplinaridade" e "educação ambiental". Esses termos foram filtrados pelo título e, ou, resumo dos artigos. Como fonte para coleta de dados utilizaram-se a base de dados Periódicos Capes. Por se tratar de uma base de dados consolidada e com acesso de forma gratuita, a busca resultou em um total de 85 artigos, compreendendo um 
espaço temporal de 3 anos (2017 a 2019). Período em que a Capes costuma avaliar a produção científica dos pesquisadores brasileiros, desta forma se analisou individualmente cada artigo, a partir da leitura dos títulos, resumos, metodologia e resultados. Após a coleta dos dados se realizou a tabulação e análise, utilizando-se do software Microsoft Excel pacote office 365.

\section{ANÁLISE DOS DADOS}

Através da pesquisa em artigos publicados no portal de periódicos da CAPES buscou-se compreender os principais temas tratados nos artigos que tinham como temas a interdisciplinaridade e a educação ambiental. Os dados foram apresentados por meio de gráficos e tabelas com os seguintes dado: quantidade de artigos publicados, autores por publicação, gênero dos autores, metodologia, palavras-chaves, área do conhecimento, região do Brasil, temas, metodologia, resultados e instituição. Como filtro para selecionar os artigos foi usado os termos interdisciplinaridade e educação ambiental, que eram encontradas nos títulos, nas palavras-chave e nos resumos. Por fim, a análise contemplou 85 artigos através do processo de análise bibliométrica.

\section{RESULTADOS E DISCUSSÃO}

Essa seção apresenta e discute os resultados obtidos com a análise dos 85 artigos encontrados na referida busca. A contagem das pesquisas e análises será apresentada por meio de tabelas e gráficos.

\subsection{Ano de publicação}

A tabela 1, expressa a quantidade de artigos publicados entre os anos de 2017 a 2019. 
Tabela 1 - Quantidade de artigos publicados de 2017 a 2019

\begin{tabular}{lc}
\hline \multicolumn{1}{c}{ Ano } & Quantidade \\
\hline 2019 & 13 \\
2018 & 25 \\
2017 & 32 \\
Não disponível & 15 \\
Total & 85 \\
\hline
\end{tabular}

Fonte: Autor.

A pesquisa analisou 85 artigos publicados no período de três anos, em 2017 foram 32 artigos, em 2018 foram 35 e no ano de 2019, apenas 13 artigos. A tabela supracitada apresenta uma redução no número de publicações sobre os temas em questão no ano de 2019.

\subsection{Quantidade de autores}

A tabela 2 expõe a relação à quantidade de autores presentes nos artigos.

Tabela 2 - Quantidade de autores por ano de publicação

\begin{tabular}{lccc}
\hline \multicolumn{1}{c}{ Autores } & $\mathbf{2 0 1 7}$ & $\mathbf{2 0 1 8}$ & $\mathbf{2 0 1 9}$ \\
\hline Um autor & 05 & 05 & 03 \\
Dois autores & 08 & 09 & 02 \\
Três autores & 05 & 03 & 05 \\
Quatro autores & 04 & 06 & 01 \\
Cinco autores & 09 & 00 & 01 \\
Seis autores & 01 & 01 & 00 \\
Sete autores & 00 & 00 & 01 \\
Oito autores & 00 & 01 & 00 \\
Total & 32 & 25 & 13 \\
\hline
\end{tabular}

Fonte: Autor.

Pode-se verificar que no ano de 2017 há predominância de artigos publicados com a presença de cinco autores, aparecendo nove vezes. No entanto, artigos com dois autores ocorreram oito vezes e apenas uma publicação apresentando seis autores. 
No ano de 2018, a predominância de publicações demonstrou um maior número com a presença de dois autores, aparecendo nove vezes. Logo, publicações com quatro autores apareceram seis vezes, tendo apenas uma ocorrência em artigos com a presença de seis e oito autores.

Em 2019, esses números variam em uma ordem decrescente, apresentando cinco publicações com três autores, três com um autor, duas com dois autores e alternando entre quatro, cinco e sete autores com apenas uma ocorrência.

\subsection{Gênero dos autores}

O gráfico 1, indica a porcentagem de autores do sexo masculino e feminino.

\section{Gráfico 1 - Gênero masculino e feminino dos autores}

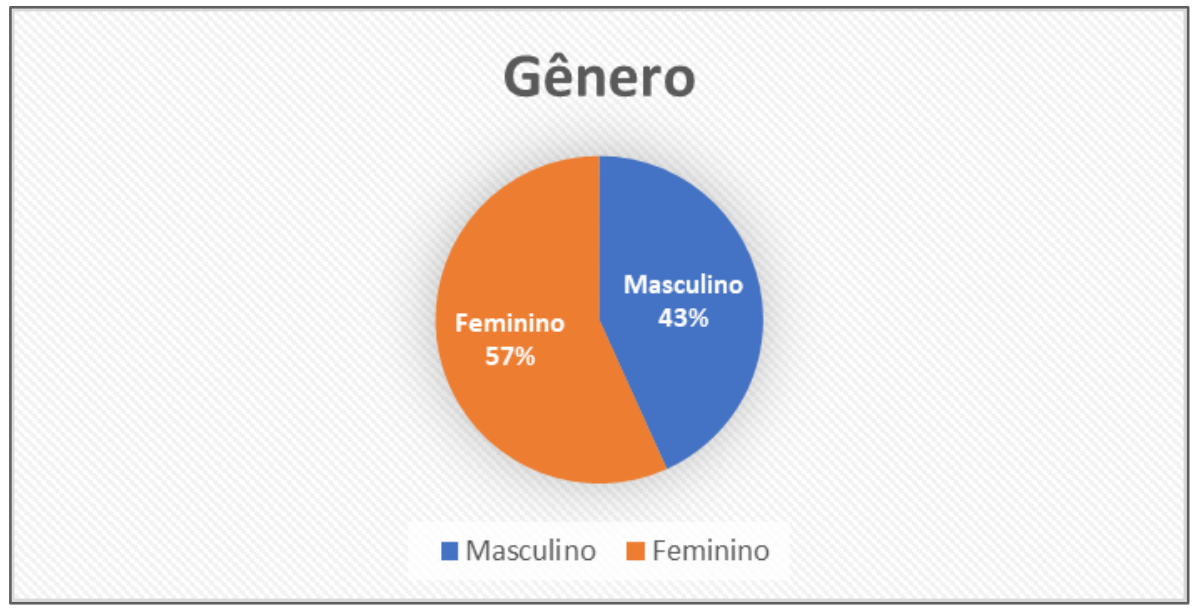

Fonte: Autor.

Com base na análise de dados contemplados nos artigos, pode-se constatar, conforme demostra a figura 1, um índice de $57 \%$ de autores do sexo feminino em relação ao sexo masculino, que representa $43 \%$. Os dados demostram a hegemonia do sexo feminino, que corrobora com a percepção dos enfatizados. É visível que o sexo feminino se destaca no cenário da Interdisciplinaridade, tendo em vista estudos que relatam sobre a feminilização em áreas de predominância feminina, como o campo da educação tradicional, retomando a aspectos como desigualdade de gênero (CARVALHO 
E SCHMIDT, 2008). Entretanto, quando correlacionados os temas interdisciplinaridade e

EA, podemos ver que trabalhos com autoras, possuem porcentagem maior do que os do sexo masculino, assim reafirmando o empoderamento feminino, porém em vários campos do conhecimento não se limitando somente à educação. Isso enfatiza a busca da mulher pelo seu espaço em uma sociedade com histórico de desigualdade de gênero.

\subsection{Metodologias}

O gráfico 2, apresenta os tipos de metodologias presentes nos periódicos.

\section{Gráfico 2 - Tipos de metodologias presentes nos resumos na plataforma periódicos Capes}

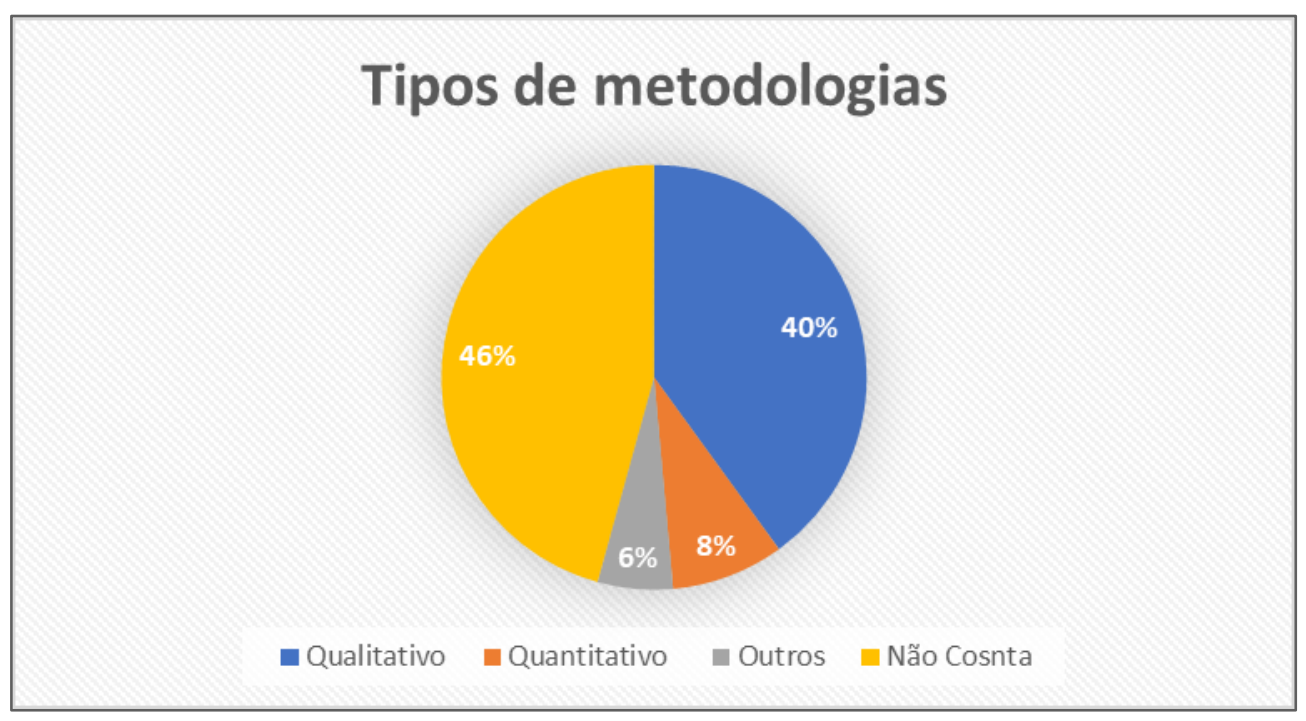

Fonte: Autor.

Nas análises dos artigos, verificou-se o tipo de metodologia adotada pelos autores em cada artigo. Desta forma, pode-se determinar que $40 \%$ dos artigos possuem metodologia do tipo qualitativa, $8 \%$ quantitativa e $6 \%$ outros tipos de metodologias. Além disso $46 \%$ dos resumos analisados não apresentava o tipo de metodologia utilizada nas suas investigações. 


\subsection{Palavras-chaves}

\section{Gráfico 3, apresenta as palavras-chave citadas nos periódicos, bem como a}

\section{frequência de suas citações.}

Gráfico - 3 Tipos de palavras chaves

\section{Palavras chaves}

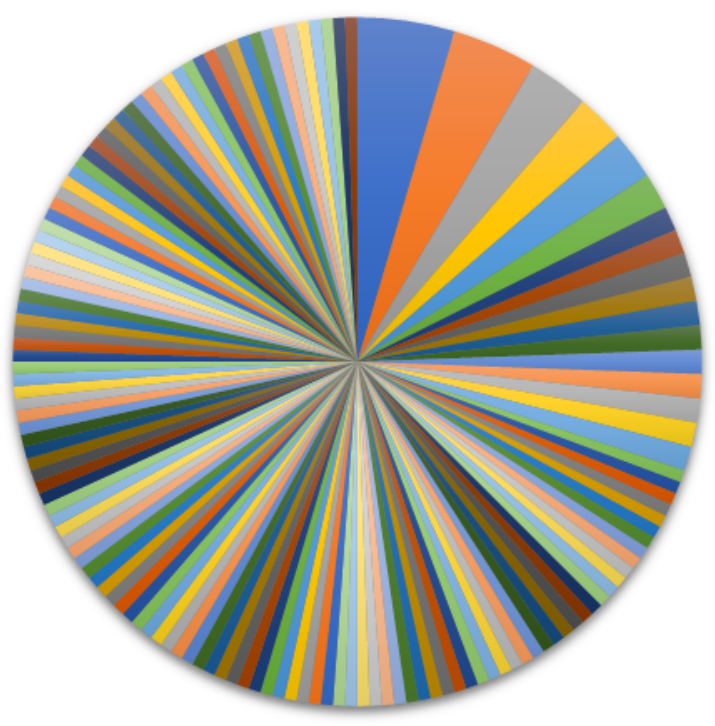

- Inter disciplinari dade

Desenvolvim ento sustentável

- Educação ambiental

- Extensão uni versitári

Projeto integrador.

- Administração em saúde.

- Alimento

Bibliog afia analitica

- Cidade sustentável

- Coleta sel etiva urbana

- Comportam ento alim enta

- Corforto ambiental

- Desenvolvim ento como Liberdade

- Direito administrativo

- Dire tos hum anos

- Educação Ambiental critica

Eficaçao Estética e Artistica

- Ensino e Relações Internacionais

- Esfera Federa

- Estudos inter disciplinares

Formaçào de professor es, técnica de ensino

- Gestão ambiental

História das R elações Internacionais

- Humanidade

Jar dinagem

- Larry Laudan

- Mestrados em Admini stração

- Maturidade físcal

- Participação social

Politica pública baseada em evidência

- Práticas inter disciplinares

Principio da eficiência

- Produção plástica

- Recidagem

- Releitura.

- Responsabili dade civil

- Segurança alimentar e nutricional

- Sistema de saúde

Sociedade civil

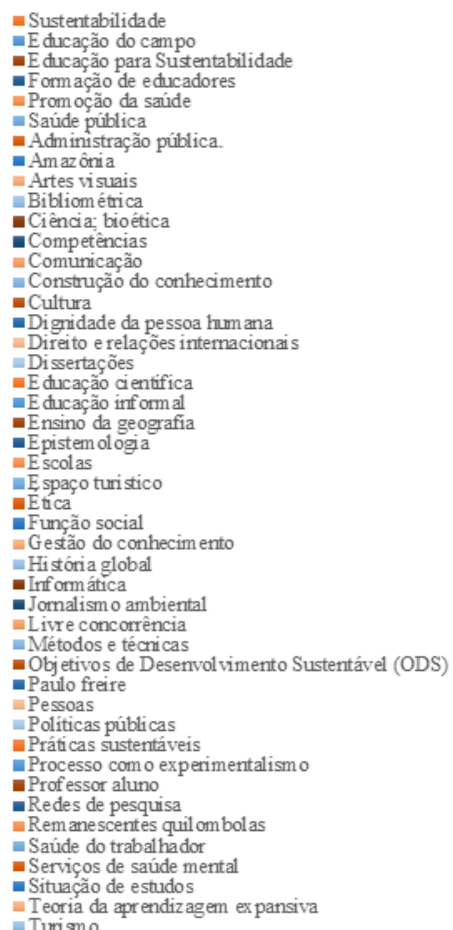

-Educação

Ensino em Gestão e Negócios

- Ensino superior

Genese do Turismo

Risco

Administração

A prendiagem es perienci

- Atenção à saúde

Caso di dático

- Ciencias sociais

- Complexidade

Condic cỗes de trabalho

Contextualiz ação

- Democracia

- Direito à saúde

Direito urbano

Eco pedagoga

Adcaçà em Administracão

Educação profíssional e tecnológica

Ensino de caencias.

Escolas promotoras de saúd

Estratégias

-Flex ografi

-Geografia

Grupos de pesquis

- Historiografía

- Intencionalidade.

- Justiça fiscal

Meio ambient

Natureza

- Pensamento s stêmico

- Politica de saúde

Povos indigenas

- Precaução

Processos e Tecnol ogia

Profissionais de Saúde

- Relacooes internacionais históricas

- Residuos sólidos urbanos

Secretariado ex ecutivo

Serviços de saúde do trabalhador

- Sociedade Turismo.

Fonte: Autor. 
De acordo com a tabela 3, observa-se que existe uma pluralidade de palavras, as quais estão presentes em vários campos do conhecimento. À medida que estas palavras-chave são citadas nos artigos torna-se visível que os temas interdisciplinaridade e educação ambiental ultrapassam as fronteiras do conhecimento. Reafirmando a ideia de LEFF (2010), que retrata a interdisciplinaridade como uma atuação híbrida entre disciplinas científicas, saberes acadêmicos e populares. (LEFF, 2010, p. 33 Apud TAGLIAPIETRA, CARNIATTO p, 86).

\section{6 Áreas de conhecimento}

O gráfico 4 apresenta as áreas de conhecimentos dos autores, quando expressos nos artigos.

\section{Gráfico 4 - Áreas de conhecimento dos autores}

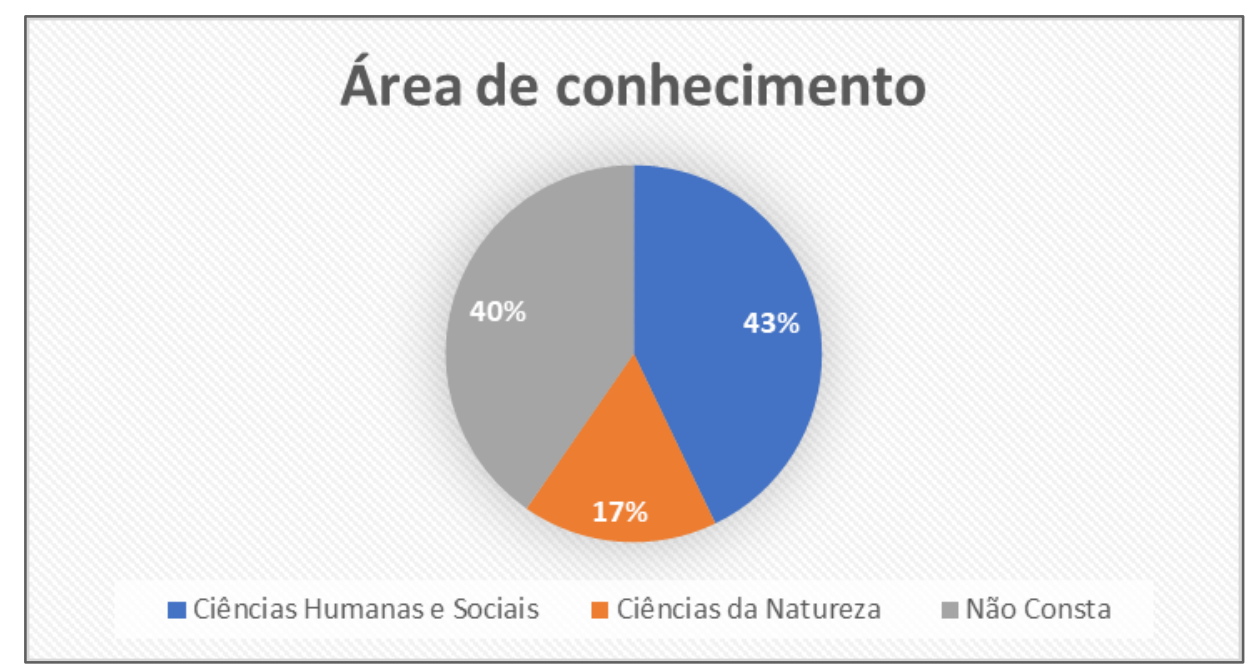

Fonte: Autor.

As áreas de conhecimento dos autores foram divididas em dois grupos: ciências humanas e sociais e ciências da natureza. Com representatividade de $43 \%$ dos artigos, a área de ciências humanas e sociais prevaleceu, demonstrando maior interesse dos autores em relação aos assuntos de interdisciplinaridade e educação ambiental, em contrapartida, $17 \%$ de representação é na área de ciências da natureza. Porém, é visível a 
significância de que $40 \%$ dos artigos analisados não apresentavam área de conhecimento, impossibilitando conhecer o campo de atuação dos autores. Para que haja uma valorização das universidades/instituições e de seus respectivos métodos de trabalho, a identificação do campo de atuação dos autores é de suma importância.

\subsection{Regiões nacionais}

O gráfico 5 apresenta a distribuição por regiões dos autores.

Figura 5 - Regiões dos autores presentes nos artigos

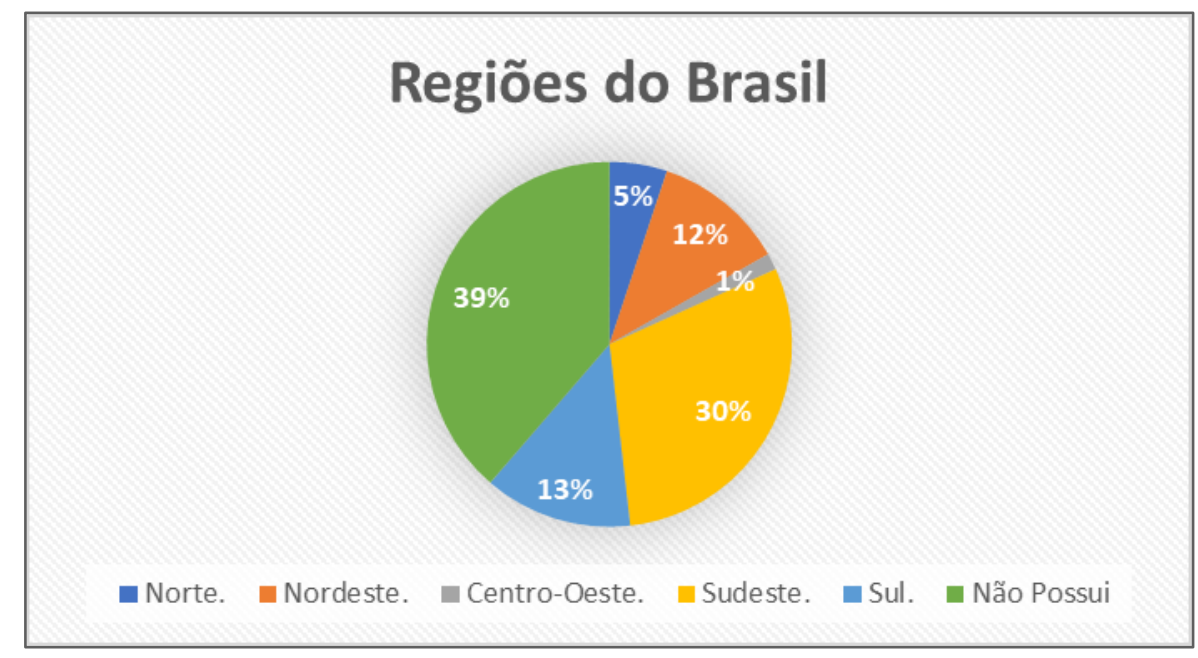

Fonte: Autor.

Quando analisadas as regiões de publicações dos autores, o destaque foi a região nordeste, a qual apresentou 39\% de autores. Logo, em seguida, a região sudeste aparece com $30 \%$ dos autores seguida da região sul com $13 \%$. A região norte com $5 \%$ e a centro-oeste com apenas $1 \%$. É importante ressaltar que $12 \%$ dos artigos verificados, quando procurado a localização dos autores, não foi possível identificar a região do mesmo. A pesquisa também demostrou que a maioria dos artigos eram nacionais, com exceção de um de nacionalidade Portuguesa. 


\subsection{Temas Abordados}

O gráfico 6 retrata sobre os temas mais abordados, extraídos através da leitura dos resumos dos periódicos Capes.

\section{Gráfico 6 - Temas}

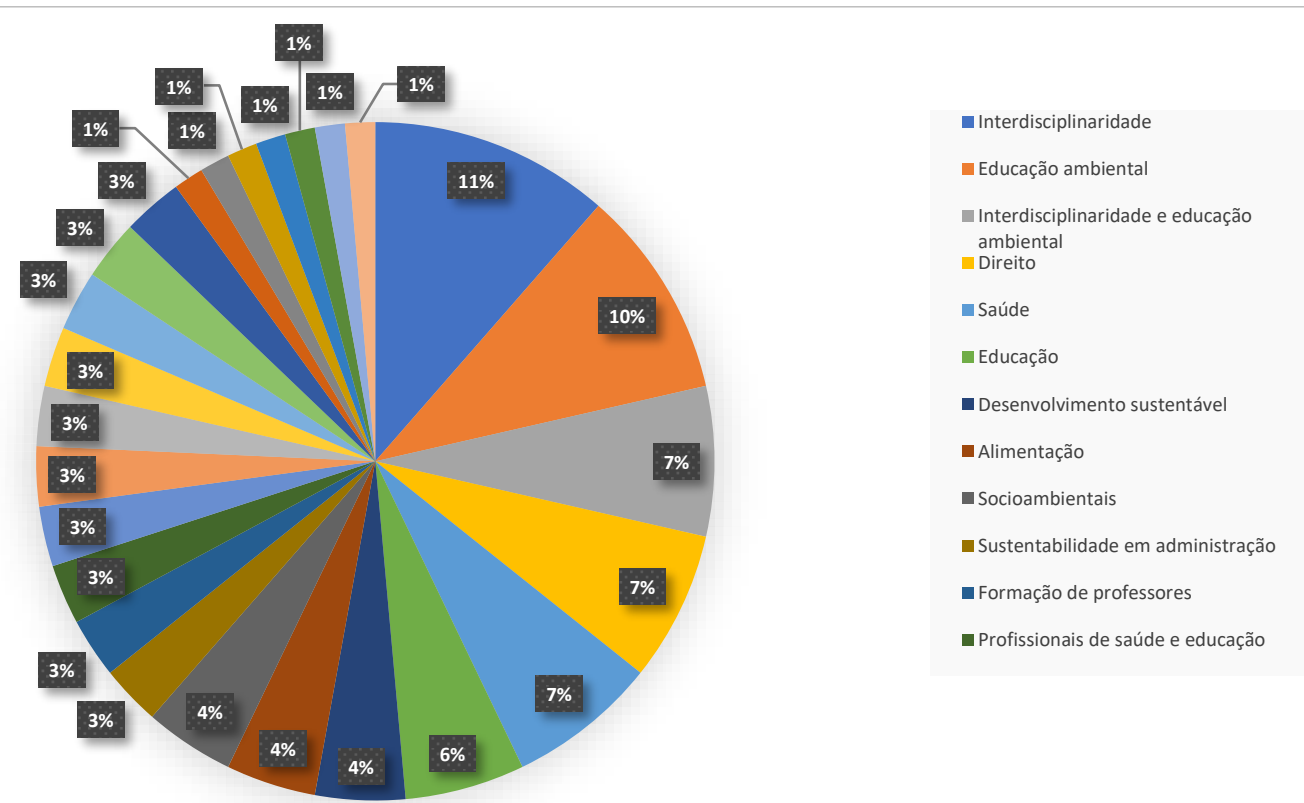

Fonte: Autor.

O tema destaque, de acordo com a tabela acima, é a interdisciplinaridade com prevalência de 8, seguida da educação ambiental. Demonstrando que as áreas em questão apresentaram maior prevalência, quando buscadas. Já no contexto de educação ambiental e interdisciplinaridade o tema teve a ocorrência de cinco vezes. Com a mesma ocorrência surgiram temas relacionados à saúde e ao direito. É possível ver na tabela, que ocorrem diversos outros temas, trazendo a ideia de que a interdisciplinaridade e educação ambiental são abordadas em uma diversidade de temáticas. Reforçando a ideia de globalização e pluralidade dos temas citados. 


\subsection{Existência de resultados nos resumos}

A tabela 3 demostra a quantidade de artigos que apresentaram os resultados em seus resumos.

\section{Tabela 3 - Resultados presentes nos artigos}

\begin{tabular}{lc}
\hline Possuem resultados & Quantidade \\
\hline Sim & 38 \\
Não & 32 \\
Total & 70 \\
\hline
\end{tabular}

Fonte: Autor.

Quando realizada a leitura dos resumos, verificou se a presença dos resultados nos textos. De acordo com a tabela supracitada, 38 dos periódicos analisados apresentaram os resultados em seus resumos. Do mesmo modo, apenas 32 não apresentaram resultados, nos resumos. Os resumos são partes importantes de um artigo, pois é a partir deles que o leitor vai decidir dar seguimento ou não a leitura. Estes devem ser compostos por partes importantes de caráter informativo e objetivo, porém podem ser simples, isso vai variar conforme o tipo de publicação e o número de caracteres. (PEREIRA, 2013).

\subsection{Instituições mais referidas}

O gráfico 7 apresenta as instituições que constavam nos resumos, salientando as que ocorreram mais vezes dos resumos. 


\section{Gráfico 7 - Instituições presentes nos artigos}

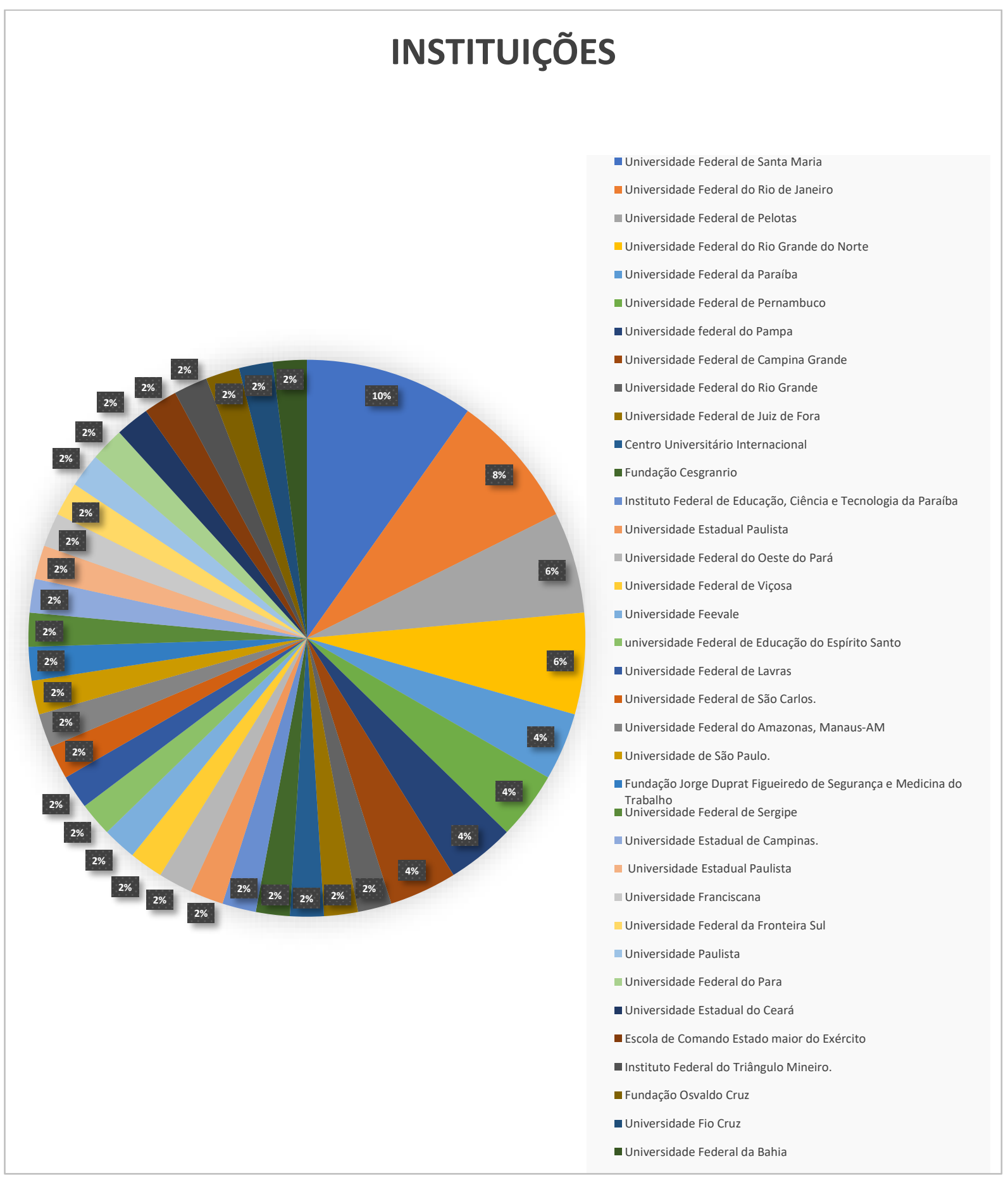

Fonte: Autor.

Com base na figura acima, é possível determinar que a instituição que teve mais artigos citados referentes ao tema é a Universidade federal de Santa Maria (UFSM), que aparece cinco vezes. A Universidade Federal do Rio de Janeiro (UFRJ) aparece quatro 
vezes, por conseguinte a Universidade Federal de Pelotas (UFPEL) e a Universidade Federal do Rio Grande do Norte (UFRN) aparecem três vezes cada. Ainda assim verificase a presença da Universidade Federal da Paraíba (UFPB), Universidade Federal de Pernambuco (UFPE), Universidade Federal do Pampa (UNIPANPA) e a Universidade Federal de Campina Grande (UFCG). As demais instituições visualizadas na tabela 6 aparecem pelo menos uma vez totalizando vinte e oito, entre institutos e universidades federais, estaduais e privadas. Além disso, o estudo apresentou um total de trinta e quatro artigos entre disponíveis e não disponíveis, que não constavam vínculo institucional.

\section{CONCLUSÕES}

Através da análise bibliométrica dos periódicos da CAPES, entre os anos de 2017 a 2019, foi possível analisar temas como interdisciplinaridade e educação ambiental. Buscou-se através da leitura dos resumos, características que reafirmem a predominância dos temas abordados dentro de um contexto global e de um pensamento crítico nas diversas áreas do conhecimento.

Partindo do pressuposto de que a educação ambiental tem caráter interdisciplinar, pode-se determinar que diversas áreas ainda não compreenderam a necessidade de se trabalhar de forma interdisciplinar. Dentro desse contexto, fica evidente que a educação precisa valorizar a integração de todos os saberes de forma interdisciplinar, atuando de forma integrada e não fragmentada para que haja o entendimento do conhecimento em toda sua complexidade.

A pesquisa teve finalidade de expor os principais pontos estudados nos artigos científicos no contexto dos temas supracitados. Mostrando um declínio das produções, entre os anos de 2017 e 2019, maior número de autores publicados em 2017, predominância do sexo feminino enfatizando o empoderamento feminino dentre às produções científicas e nas diversas áreas do conhecimento. Disparidades entre as metodologias, predominância de palavras chaves como: interdisciplinaridade, 
sustentabilidade e educação, os quais retomam à análise. Já a área de conhecimento dos autores demonstrou que o campo das ciências humanas e sociais tende a trabalhar mais com os temas.

Ao mesmo tempo os artigos são insuficientes, quando não retratam a área de conhecimento dos autores. Em relação a localização dos autores predomina a região sudeste, e o menor índice encontram-se na região centro-oeste. Em relação aos temas abordados, interdisciplinaridade e educação ambiental destacam-se como os mais relevantes.

Por fim, quanto a presença de resultados nos resumos dos 70 artigos analisados, 32 não constam os resultados. Dentre as instituições, destaca-se a universidade federal de Santa Maria (UFSM), como mais presente nos periódicos. Através da análise bibliométrica foi possível identificar que os conceitos de educação ambiental e interdisciplinaridade, apesar de um bom número de trabalhos, ainda precisam avançar nas análises científicas mais integradas, pois sabe-se que a complexidade dos temas requer esforços científicos, um desafio para todos os pesquisadores/educadores do tema.

\section{REFERÊNCIAS}

BOFF, L. Sustentabilidade: o que é: o que não é. $5^{a}$ ed. Petrópolis-RJ: Vozes, 2016.

BRANDALISE, L.T.; BERTOLINI, G.R.F.; HOSS, O.; ROJO, C.A. A. Educação e gestão ambiental: sustentabilidade em ambientes competitivos. $2^{\text {a }}$ ed. Cascavel, Paraná: DRHS, 2017.

COIMBRA, José de Ávila Aguiar. Considerações sobre a interdisciplinaridade. In: PHILIPPI JR, Arlindo et al. (Org.) Interdisciplinaridade em Ciências Ambientais.São Paulo: Ed. Signus, 2000.

FÁBREGA, Eunice Pessin. Interdisciplinaridade. São Paulo, 2004.

FAZENDA, Ivani Catarina Arantes. Didática e interdisciplinaridade. 8. ed. São Paulo: Papirus, 2003. (Coleção Práxis). 
FAZENDA, I. C. A. (Org.); Lenoir (Org.); PIMENTA, S. (Org.); KENSKI, V. (Org.). Didática e Interdisciplinaridade. 9a. ed. Campinas: Papirus, 2005.

FAZENDA, Ivani. A Interdisciplinaridade: um projeto em parceria. São Paulo: Loyola, 1993.

FERRARI, S. L. P.; Cribari-Neto, F. Beta regression for modelling rates and proportions. Journal of Applied Statistics, v. 31, n. 7, p. 799-815, 2004.

FERREIRA, M. P. A bibliometric study on ghoshal's managing across borders. The Multinational Business Review, Reino Unido, v. 19, n. 4, p. 357-375, nov., 2011.

FLORIANI, D. Diálogos interdisciplinares para uma agenda socioambiental:breve inventário do debate sobre ciência,sociedade e natureza. Desenvolvimento e Meio Ambiente, n. 1, p. 2139, jan./jun. 2000. Editora da UFPR, 2000.

MEDINA, N.M.; SANTOS, E.C. Educação Ambiental: uma metodologia participativa de formação. Petrópolis - SP: Vozes, 1999.

ROCHA, Paulo Ernesto Diaz. Trajetória e perspectivas da Interdisciplinaridade ambiental na pós-graduação brasileira. Ambiente \& Sociedade. [online]. v. VI n. 2 jul./dez, 2003

SANTOS, M. 1992: A redescoberta da Natureza. São Paulo: Estudos Avançados, São Paulo, v.6, n.14, jan./abr. 1992.

SANTOS, M. O Brasil: território e sociedade no início do século XXI. 13 ed. Rio de Janeiro: Record, 2000.

TRISTÃO, Martha. A educação ambiental e a emergência de uma cultura sustentável no cenário da globalização. Revista Internacional Interdisciplinar. Interthesis, 2012, 9.1: 207-222.

NASCIMENTO, Priscila Thais Bezerra; MENDES, Tamires Gabryele Lima; BEZERRA, Jaelson Melo. Educação Ambiental e projetos interdisciplinares: um olhar sob os anos finais do ensino fundamental. Revista Brasileira de Meio Ambiente, 2018, 2.1.

GUIMARÃES, M. Educação Ambiental: No consenso um embate?.5 ed. Campinas: Papirus, 2000.

; Lei Federal. No 9.795, de 27 de abril de 1999. Dispõe sobre a educação ambiental, institui a Política Nacional de Educação Ambiental e dá outras providências.

AYRES, F. G. S.; FILHO, J. B.B. O exercício das liberdades, o combate à pleonexia e a educação ambiental no processo do desenvolvimento. Revista Brasileira de Ciências Ambientais, [S.I], n.7, p.27-33, ago.2007. 
SANTOS, Boaventura de Sousa. Um discurso sobre as ciências na transição para uma ciência pós-moderna. EstudosAvançados.[online].[S.I.]:v. I2, n.2, p. 46-71, 1988.

LEÃO, A.L.C.; SILVA, L.M.A. Fazendo Educação Ambiental. $4^{a}$ ed. Recife: CPRH - Companhia Pernambucana do Meio Ambiente, 1999.

LEFF, E. Saber ambiental: Sustentabilidade, Racionalidade, Complexidade, Poder. Petrópolis, RJ: Vozes, 2001.

CARVALHO, I.C.M. Em direção ao mundo da vida: interdisciplinaridade e Educação Ambiental / Conceitos para se fazer Educação Ambiental. Brasília: IPÊ - Instituto de Pesquisas Ecológicas, 1998.

PEREIRA, Antonio. A educação não formal e educação social na ordem do dia: entre conflitos e possibilidades educativas. In: Revista Metáfora Educacional (ISSN 1809-2705) - versão online, n. 15 (jul. - dez. 2013), Feira de Santana - Bahia (Brasil), dez./2013. p. 129-148. 